\title{
The Impact of Social Network Media on Brand Equity in SMEs
}

\author{
Mohammad Reza Nemat Gorgani ${ }^{1}$
}

\begin{abstract}
:
Given the virtual world's controlling role in everyday life, no one can ignore its crucial impacts on the physical world. In this term social network media play a considerable role in peoples' daily lives and business by information sharing and the impressions of friends' comments on own view. Dealing with change, continuing to develop in the dynamic marketplace furthermore, access to information on a level never experienced before are possible benefits to companies;Social media influences companies' strategies because of the wealth of information that customers yield while interacting on platforms; In this story Facebook with 1.55 billion monthly active users is the prominent social network among businessmen, consumers and clients. This paper aims to analysis the impact of electronic word of mouth marketing (EWOM) in social network on brand equity of "Kia gallery" contemporary jewelry design company in Iran. Thus, 350 clients, was defined as study population and their behavior in Facebook was investigated. The result of the research described in this article illustrate that the EWOM has a positive effect on brand awareness and brand image in addition they influence the consumer attitude which has impact on customer purchase intention and value of the brand.
\end{abstract}

Key words: social network; word of mouth marketing; consumer behavior; brand equity, Social network-facebookEWOM- brand awareness- brand image-consumer attitude-consumer behavior, SMEs

\section{Introduction}

Nowadays there is no any border between internet and social media network in whether business world or private life. It has become an important link to connect the people all over the world. Social networking sites (SNS) such as Facebook, Twitter, and Google+ are low-cost tools that can promote the creation of social connections by providing a convenient platform (Bargh \& McKenna, 2004); i.e. Worldwide, there are over 1.65 billion monthly active Facebook users which is a 15 percent increase year over year. (Source: Facebook as of 4/27/16), every 60 seconds on Facebook: 510 comments are posted, 293,000 statuses are updated, and 136,000 photos are uploaded (Source: The Social Skinny). Facebook Commerce is one form of the concept of Social Commerce, with E-Commerce uses the Facebook platform to showcase products, shopping goods, and transaction directly in the Facebook (Syuhada \& Gambetta, 2013).

Companies are using social media (SM) not only for digital advertising, but also for handling customer services, mining innovation ideas, and creating engaged brand communities (Enginkaya \& Y1lmaz, 2014),Using SM is not an easy task and may require new ways of thinking (Kaplan \& Haenlein, 2010). They [social networking sites] have transformed consumers from silent, isolated and invisible individuals, into a noisy, 
public, and even more unmanageable than usual, collective (Patterson, 2012).

Social media marketing is not only for multinational companies but also can be used for SMEs (small and medium enterprises). SMEs are different from general businesses due to the following factors, i.e. limited capital, number of workers, level of competition and strict product specialization because there are enormous number of buyers and sellers (Syuhada \& Gambetta, 2013).SMEs in Iran are under regulation of Small Industries and Industrial Parks Organization (ISIPO) which is a developmental organization affiliated to the Ministry of Industry, Mine and Trade. It was established by amalgamating "Iran Small Industries Org." with "Iran Industrial Estate Co." in the second half of the year 2005. Considering the fact that $92 \%$ of Iran industries are SMEs and regarding the vital role of SMEs in the economic growth, in this paper, the impact of social media network on the brand equity in this sector was investigated.

\section{Consumer behavior}

Social network commerce focuses on how e-commerce sway their online social activities to achieve a competitive advantage (Schmidt \& Iyera, 2015).

Based on netnographic, sociology literature and marketing literature on social network analysis, a common friend in a social network becomesan effective medium of information dispersion.

As assumed by Bass (1969), word-of-mouth (WOM) is a uniform interpersonal influence generated by a network of consumers who are connected to one another. From a study conducted by Kozinets, Valck, Wojnicki and Wilner (2010), WOM has evolved over time through changes in communication technology from the 'organic interconsumer influence model', where WOM influence occurs at an one-on-one basis between two consumers without any interference from marketers, to 'the network coproduction model' in which WOM is directly prompted by marketers with the active co-production from virtual consumer networks(Thoumrungroje, 2014).

As professor Philip Kotler has foreseen that marketers should fundamentally rethink the processes through which they identify, communicate and provide value for the clients (Kotler \& Armstrong, 2008). Larry Weber argues that intelligent marketers should encourage consumers' participation to social networks to which they wish to pertain and where the dialogue with the consumers and between them can be solved (Webber, 2009). Online marketers may influence the buying decision process of online consumers by using traditional marketing instruments and mainly by creating and delivering adequate online experience, of Web experience (Cetina, Munthiu, \& et al, 2012). Brands provide a valuable instrument to influence consumer behavior and sustainable incomes for the organizations brands get strengthened through creating participation, allowing external audiences to identify with them, and become involved in (Yan, 2011).

\section{Methodology}

Object of research described in this article is the impact of Social network media on brand equity. For data gathering the scholar was used a questionnaire which was designed under electronic oral advertising in SM, brand image, brand awareness, brand 
attitude and brand equity. The reliability of that tool was measured by Cronbach's alpha in SPSS which all the questions were more than 0.8. To analyze the data collected at the level of analytical statistics, The main goal of research is to monitor influence of EWOM in Facebook on official brand equity. In this research "Kia gallery" -contemporary jewelry design company- clients was selected as research population.

\subsection{Material and research model}

After qualitative phase, items were generated to build a multidimensional scale. Then the structural equation modeling was used to examine the hypothesis and investigate the causal relations between the variables in the analytical model. It does by seeking underlying unobservable (latent) variables that are reflected in the observed variables (manifest variables). Factor analysis is based on the correlation matrix of the variables involved, and correlations usually need a large sample size before they stabilize. In multivariate statistics, Confirmatory factor analysis (CFA) is a statistical technique used to verify the factor structure of observed variables. CFA allows the researcher to test the hypothesis that a relationship between observed variables and their underlying latent constructs exists. A method to examine the causal relationships between variables or multivariate analysis is structural equation modeling with latent variables. In this study, Structural equation modeling (SEM) is used to assess and defines latent variables using one or more observed variables, and a structural model that imputes relationships between latent variables.

\subsubsection{Factor analysis of Oral Electronic Advertising}

At first confirmation is related to impact of electronic oral advertising, where short reflections on various topics connected with business in form of blogs are published. In compliance with this the Confirmatory factor was analyzed: Confirmatory factor analysis results showed the validity of the questions due to the significant of factor loading, because it was larger than 0.3 and put goodness factors in the proper range.

\subsubsection{Factor analysis of influenced factors by Oral Electronic Advertising}

In order to confirmation of hypotheses, Pearson correlation and structural equation modeling was used. All the relationships between variables is positive with highest correlation coefficient 0.787 (electronic oral advertising by company and electronic oral advertising by consumer) and the lowest correlation coefficient 0.525 (between brand image and brand awareness).

Structural equation modeling is used to test research hypotheses. One of the advantages of SEM is analyzing the binary relationship between two variables, at the same time, by considering the impact of all relations. In this study, two-stage approach in implementing structural equation modeling was used, the first phase was the confirmatory factor analysis; with the implementation of confirmatory factor analysis has been fulfilled two purposes: first, validity, and, second, the first phase of Model structure; in the second stage with the help of structural equation analysis estimated impact of coefficients. 


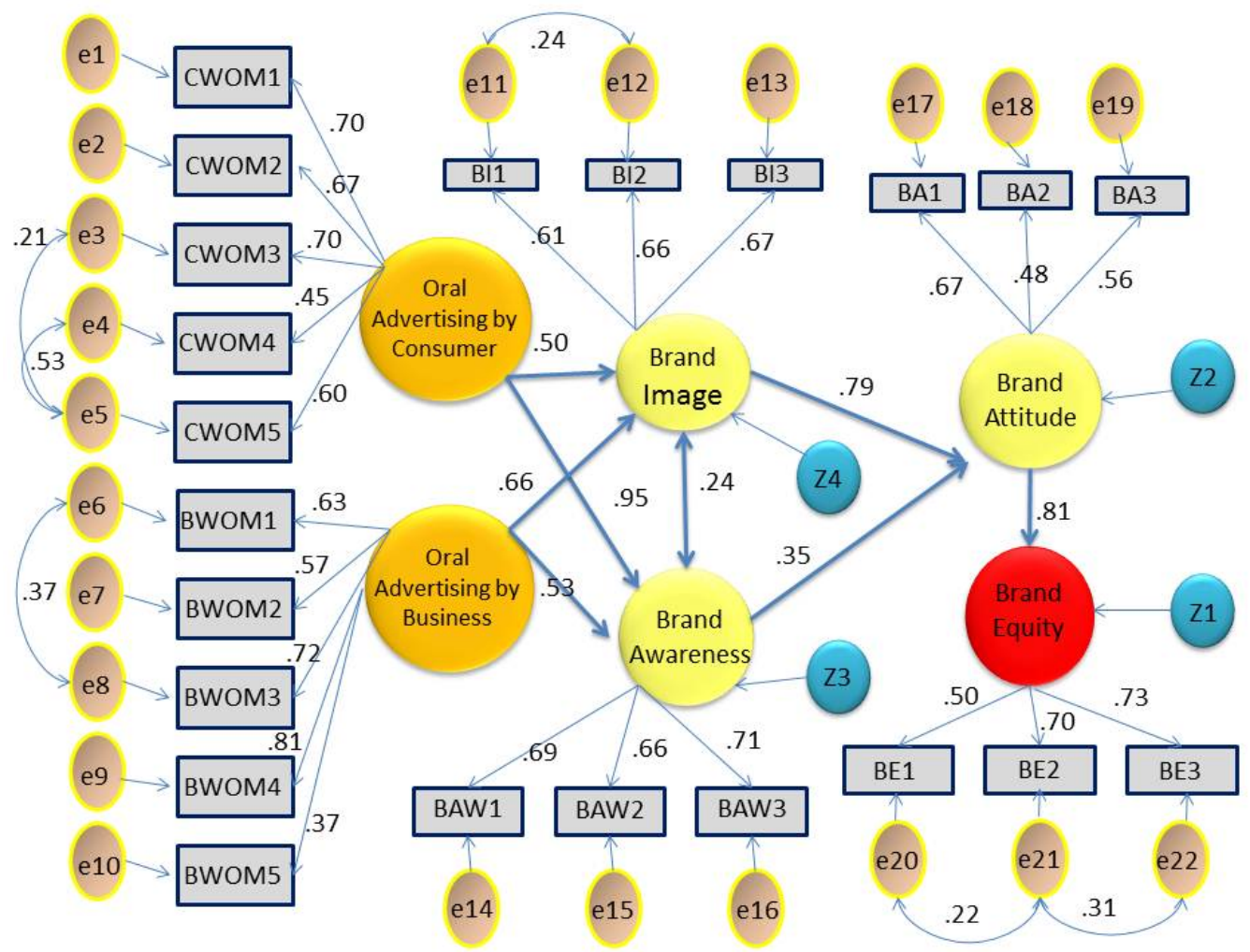

Figure 1(SEM)

\section{Analysis and estimation parameters}

Almost all indicators are within a reasonable range and can be used for ensuring the structure of the model. In addition to the overall model the details should be verified. Therefore, to determine the factor loadings and structural factors are discussed. The goodness detail factors- CR and P- are illustrating that the loading factors are significant and Structural coefficients are less than 0.05 so the goodness of the model proved by the goodness details factor.

Table 1(goodness-fit of SEM factors)

\begin{tabular}{|c|c|c|c|c|c|c|c|}
\hline & & & $\begin{array}{l}\text { Estimat } \\
\mathrm{e}\end{array}$ & $\begin{array}{l}\text { Standar } \\
\text { dized } \\
\text { Estimat } \\
\text { e }\end{array}$ & S.E. & C.R. & $\mathbf{P}$ \\
\hline Brand image & $<---$ & Oral advertising by Consumer & 0.408 & 0.501 & 0.059 & 6.964 & $* * *$ \\
\hline Brand image & $<---$ & Oral advertising by Business & 0.401 & 0.658 & 0.047 & 8.592 & $* * *$ \\
\hline $\begin{array}{l}\text { Brand } \\
\text { awareness }\end{array}$ & $<---$ & Oral advertising by Consumer & 1.083 & 0.946 & 0.143 & 7.575 & $* * *$ \\
\hline $\begin{array}{l}\text { Brand } \\
\text { awareness }\end{array}$ & $<---$ & Oral advertising by Business & 0.452 & 0.528 & 0.1 & 4.515 & $* * *$ \\
\hline $\begin{array}{l}\text { Brand } \\
\text { awareness }\end{array}$ & $<---$ & Brand image & 0.343 & 0.244 & 0.2 & 1.718 & $.86^{0}$ \\
\hline $\begin{array}{l}\text { Brand } \\
\text { attitude }\end{array}$ & $<---$ & Brand image & 0.929 & 0.788 & 0.123 & 7.57 & $* * *$ \\
\hline
\end{tabular}




\begin{tabular}{|l|l|l|l|l|l|l|l|}
\hline $\begin{array}{l}\text { Brand } \\
\text { attitude }\end{array}$ & $<---$ & Brand awareness & 0.293 & 0.349 & 0.066 & 4.46 & $* * *$ \\
\hline Brand equity & $<---$ & Brand attitude & 0.555 & 0.815 & 0.079 & 7.01 & $* * *$ \\
\hline cwom3 & $<---$ & Oral advertising by Consumer & 1 & 0.704 & & & \\
\hline cwom2 & $<---$ & Oral advertising by Consumer & 1.112 & 0.669 & 0.104 & 10.897 & $* * *$ \\
\hline cwom1 & $<---$ & Oral advertising by Business & 1.065 & 0.705 & 0.093 & 11.391 & $* * *$ \\
\hline bwom3 & $<--$ & Oral advertising by Business & 1 & 0.716 & & & \\
\hline bwom2 & $<---$ & Oral advertising by Business & 0.597 & 0.571 & 0.06 & 9.984 & $* * *$ \\
\hline bwom1 & $<--$ & Oral advertising by Business & 0.961 & 0.639 & 0.069 & 13.896 & $* * *$ \\
\hline baw1 & $<---$ & Brand awareness & 1 & 0.694 & & & \\
\hline baw2 & $<--$ & Brand awareness & 0.929 & 0.664 & 0.088 & 10.601 & $* * *$ \\
\hline baw3 & $<---$ & Brand awareness & 0.861 & 0.706 & 0.077 & 11.153 & $* * *$ \\
\hline bi2 & $<---$ & Brand image & 1.093 & 0.661 & 0.098 & 11.144 & $* * *$ \\
\hline bi3 & $<---$ & Brand image & 1.204 & 0.674 & 0.124 & 9.725 & $* * *$ \\
\hline bi1 & $<--$ & Brand image & 1 & 0.615 & & & \\
\hline be3 & $<---$ & Brand equity & 1.561 & 0.726 & 0.215 & 7.252 & $* * *$ \\
\hline be1 & $<--$ & Brand equity & 1 & 0.495 & & & \\
\hline be2 & $<---$ & Brand equity & 1.823 & 0.696 & 0.231 & 7.881 & $* * *$ \\
\hline ba3 & $<---$ & Brand attitude & 0.81 & 0.555 & 0.085 & 9.496 & $* * *$ \\
\hline ba2 & $<---$ & Brand attitude & 0.825 & 0.483 & 0.099 & 8.35 & $* * *$ \\
\hline ba1 & $<--$ & Brand attitude & 1 & 0.668 & & & \\
\hline cwom4 & $<---$ & Oral advertising by Consumer & 0.807 & 0.453 & 0.106 & 7.574 & $* * *$ \\
\hline cwom5 & $<---$ & Oral advertising by Consumer & 0.9 & 0.596 & 0.082 & 11.033 & $* * *$ \\
\hline bwom4 & $<---$ & Oral advertising by Business & 0.927 & 0.807 & 0.067 & 13.937 & $* * *$ \\
\hline bwom5 & $<---$ & Oral advertising by Business & 1.052 & 0.873 & 0.071 & 14.763 & $* * *$ \\
\hline & & & & & \\
\hline
\end{tabular}

These findings are discussed below. A summary of the hypotheses test results is provided in above tables how the results and illustrate that brand image and band awareness, and brand attitude and brand equity integration were positively influenced by electronic oral advertising (EWOM). These results basically support all of below hypotheses.

Table 2(goodness-fit of SEM factors)

\begin{tabular}{|c|c|c|}
\hline Result & Hypotheses & \\
\hline supported & Electric oral advertising by business in SMaffect brand image of consumers & \\
\hline supported & Electric oral advertising by business in SM affect brand awareness of consumers & \\
\hline supported & Electric oral advertising by consumer in SM affect brand image of consumers & \\
\hline supported & $\begin{array}{l}\text { Electric oral advertising by consumer in SM affect brand awareness of } \\
\text { consumers }\end{array}$ & \\
\hline ted & Brand image of the company affect brand attitude of consumers & \\
\hline Rejected & orand awareness of consumers & 6 \\
\hline supported & Brand awareness of the company affect brand attitude of consumers & 7 \\
\hline supported & Brand attitude of the company affect brand equity of consumers & 8 \\
\hline
\end{tabular}

\section{Results}

Structural equation modeling and its significance level was proved the electronic oral advertising- electronic word of mouth- in social media network, through company activities impact the brand image, brand awareness, brand attitude and brand equity. On 
the other hand the electronic word of mouth by consumers in SM can have significant impact on brand image and brand awareness, however the brand image have no any influence on brand awareness.

\section{Conclusion and limitations}

This paper has provided empirical justification for a model that identifies the impact of electronic word of mouth in social media network on brand equity. In addition provide EWOM enhance the brand image, brand awareness, brand attitude and brand equity. These are important points because especially SMEs may sustain their position through the effective use of stated factors in social media network (SMN). The study analyzed the Facebook accounts of an Iranian contemporary jewelry design company. The findings enables to comment on performance social media use in terms of new marketing strategy in SMEs.

According to these findings, we can summarize that, eWOM sources play an important role in the brand equity through the brand image, brand awareness and brand attitude.

As all studies contain some boundaries, this study has some limitations too. This paper investigated the Facebook users and business page of the company in this social media in order to the high rank of Facebook in number of user and active comments; Additionally research other social media mediums should be observed (e.g. Google+, Instagram, Twitter etc.) in the future as well. Future researchers should conduct interviews with other social media user and compare the result of that investigation.

\section{References}

Bargh , J., \& McKenna, K. (2004). THE INTERNET AND SOCIAL LIFE. Annual Review of Psychology, 573590.

Cetina, I., Munthiu, m.-C., \& et al. (2012). Psychological and social factors that influence online consumer behavior. Social and Behavioral Sciences, 184-188.

Enginkaya, E., \& Yilmaz, H. (2014). What drives consumers to interact with brands through social media? A motivation scale development study. Social and Behavioral Sciences, 219-226.

Kaplan, A., \& Haenlein, M. (2010). Users of the world, unite! The challenges and opportunities of Social Media. Business Horizons, 59-68.

Kotler, P., \& Armstrong, G. (2008). Principles of Marketing. New Jersey: Pearson Education International.

Patterson, A. (2012). Social-networkers of the world, unite and take over: A meta-introspective perspective on the Facebook brand. Journal of Business Research, 527-534.

Schmidt, K., \& Iyera, K. (2015). Online Behaviour of Social Media Participants' and Perception of Trust, Comparing Social Media Brand Community Groups and Associated Organized Marketing Strategies. Social and Behavioral Sciences, $432-439$.

Syuhada, A., \& Gambetta, W. (2013). Online Marketplace for Indonesian Micro Small and Medium Enterprises Based on Social Media. Procedia Technology, 446 - 454.

Thoumrungroje, A. (2014). The Influence of Social Media Intensity and EWOM on Conspicuous Consumption. Social and Behavioral Sciences, 7 - 15.

Webber, L. (2009). Marketing to the Social Web. How digital customer communities build your business. New Jersey: Wiley.

Yan, J. (2011). Social media in branding:Fulfilling a need. Journal of Brand Management, 688-696. 